\title{
The Integration of Information and Communication Technologies (ICTs) in the Teaching of Mathematics in Secondary Schools: an Ecosystemic Approach
}

\author{
Keramida Konstantina \\ Doctorate of Applied Information, University of Macedonia \\ Teacher of Applied Information in Secondary Education, Greece \\ keramidakon@gmail.com
}

\section{Doi:10.5901/jesr.2014.v4n3p187}

\begin{abstract}
The rate at which the ICTS (Information and Communication Technologies) are introduced into the educational process is very slow in spite of the materialized high ICTs investment in the sector. The purpose of this thesis is to investigate the factors, which lead to the observed low rate of ICTs adoption in the process of Maths teaching in the secondary education in Greece. The use of ICTs by the Maths teachers is distinguished in two categories: use for the teachers' own personal needs and use in class. By using an ecosystemic approach, the ICTs are specified as invaders into the school environment - the ecosystem disturbing the existing balance among its elements - computer applications and teachers. The empirical exercise included the 237 secondary education schools in the Prefecture of Thessaloniki together with the 742 Maths teachers of these schools. Semi-structured interviews and a questionnaire survey were carried out in 2006-07. The collected data were analyzed by using the Latent Variable Models. The LISREL software was used.The results show a strong two-way relationship between Mathsteachers' use of ICTs for their own needs and their use in class. "Fear" of ICTs use in class, as well as teacher-collaboration, and favorable-to-ICTs school environment are among the factors which affect significantly the ICTs adoption in class.
\end{abstract}

Keywords: Information and Communication Technologies (ICTS), Maths Teaching, Secondary Education, Ecosystemic Approach, Latent Variable Models, LISREL.

\section{Introduction}

The rate at which the ICTs (Information and Communication Technologies) are introduced into the educational process is very slow in spite of the materialized high ICTs investment in the sector (Becker, 2000a, Cattagni \& Farris, 2001, Loveless, 1996, Cuban, 1999, Kasimati \& Gialama, 2001, Triantafillou, 2002). The purposes of this paper are a) to investigate the role of teachers and school environment in the degree of ICTs use b) to identify the factors which lead to the observed low rate of ICTs adoption in the process of Maths teaching in the secondary education of Greece. The paper focuses on the fear and the prejudice of teachers for ICTSSs use in the classrooms.

The high investment for ICTs creates expectations for high rate of introduction of ICTs into the educational process. However, the results of international organisms like as OECD, Eyridice, ETD show that the rate at which the ICTs are introduced into the educational process is very slow in spite of the materialized high ICTs investment in the sector.

The use of ICTs by teachers during the lessons, affects in a positive way the knowledge (Loveless, 1996). The students using ICTs laboratories have better grades than the students who didn't have access to the ICTs. However, the extent of using the ICTs by the teachers during the process of learning isn't sufficient (Becker, $2000 \mathrm{a}$, Cattagne \& Faris, 2001).

\section{The Theoretical Model}

The findings of several researches were the motivation to investigate the factors, which lead to the low rate of ICTS adoption in the educational process (Kynigos, 2001, Wendy, 2001, Ana \& Viega, 2002, Li, 2003, Gunilla \& Jorden, 2004). This paper case studies the process of Maths teaching in the secondary education of Greece. Maths was selected because of the historical meaning which have as science, the basic and important role of Maths in the secondary education and the majority of the computer applications which are related to Maths.

The use of ICTs by the Maths teachers is distinguished in two categories: a) use for the teachers' own personal 
needs and b) use in classroom. Several researches show that the Maths teachers use the ICTs for the preparation of teaching, for searching information, for exchange aspects e.t.c. In addition, using ICTs by the teachers in the classroom creates an interactive environment of learning.

According to the above, this paper a) investigates the relationship between the uses of ICTs by Maths teachers and the rate of adoption of ICTs in the educational process and $b$ ) identifies the factors, which influence this relationship (Amartya, 1999). The factors of adoption of ICTs in the classrooms are distinguished in two categories: a) internal factors, like as phobia, prejudice, stress of Maths teachers for using ICTs and b) external factors, like as the school environment (see Figure 1)

Figure 1. The Theoretical Model

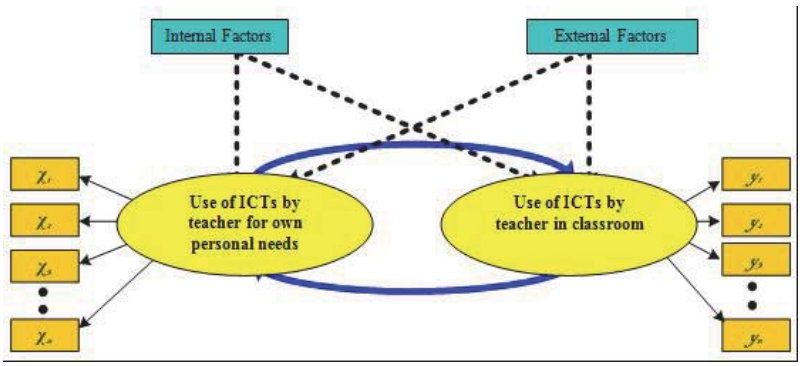

Source: Keramida, 2010

The use of ICTs, according to an ecosystemic approach, which applied by Zhao and Frank in 2003, are specified as invaders in the school environment (ecosystem), disturbing the existing balance among its elements which are the computer applications and the teachers. The ecosystemic approach focuses on the dynamic process of interaction between the Maths teachers and the ICTs, taking into account the following seven parameters:

1. School as ecosystem. It is a complex system of many parts and relationship of both biotic (teachers, students, parents, administration) and abiotic components (physical setting, location of the computers, grades and subjects of teaching).

2. Teachers as individuals and members of a species. Teachers as human beings are selfish in that they are primarily concern with the well-being of their classrooms. But they also live and work in social groups and know that they may need help from other some times. Teachers support each other because of their common interests.

3. External innovation as invasion. Computer uses promoted by techno-enthusiasts to schools, are invading species. So the successful adoption depends on their compatibility with the teaching environment, including the teachers and other species.

4. Computer uses as species. We developed a framework for understanding technology uses in school from an ecological perspective. We treat the types of the computer use by teachers as indicators of classroom ecosystem. There are two main types of uses in terms of the purpose of use: a. for the teacher's own personal needs and by teachers in class.

5. Interacting with the environment and the role of the teaching ecosystem. Our framework places emphasis on the dynamic process between the teacher and the computer.

6. Professional development as opportunity for species-species co-evolution and mutual adaptation.

7. Teacher predispositions (like as fear, prejudice e.t.c.) for the compatibility.

\section{The Data}

The empirical exercise included the 237 secondary schools in the Prefecture of Thessaloniki together with the 742 Maths teachers in these schools. The sample covers the $10 \%$ of the population. Semi-structured interviews and questionnaire survey were carried out in 2006-2007. From 742 Maths teachers the 606 filled in the questionnaire correctly. For the semi-structured interviews was selected by random stratification a sample of 60 teachers. The semi-structured interview includes set of questions about technology infrastructure, policy, investment and beliefs regarding technology. The basic 
result of these interviews was that all the teachers use the ICTs for their own personal needs but avoid using of computers in the classrooms. The survey included 19 various format items (Likert Scale, Multiple Choice and Fill in the Blanks).

The collected data were analyzed by using the Latent Variable Models (Gujarati, 1980). The LISREL software was used. We create seven cases of model, which identify the factors of successful adoption of ICTs in the process of Math teaching in the secondary education of Greece. Every case of the Latent Variable Models includes two basic models:

1. The Structural Model

2. The Measurement Models

The general form of the structural model includes the following three matrix equations:

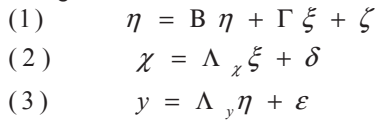

The variables of the Latent Variable Models are the following:

Table 1. Variables of LVM

\begin{tabular}{|c|c|c|c|}
\hline $\begin{array}{l}\text { Symbol } \\
\text { of LVM }\end{array}$ & \begin{tabular}{|l|} 
Symbol of \\
Exercise Model
\end{tabular} & Description & Indicators \\
\hline$\eta_{1}$ & SUCC_T & $\begin{array}{l}\text { Success in the use of ICTs by the } \\
\text { teachers for their own benefit. }\end{array}$ & $\begin{array}{l}\text { (1) ADMIN (use of ICTs by the teacher for administrative } \\
\text { tasks at school) } \\
\text { (2) ADM } \\
\text { (3) PREP (use of ICTs by the teacher for the preparation of } \\
\text { courses) } \\
\text { (4) PREPA } \\
\text { (5) OWN_ed (use of ICTs by the teacher for his information } \\
\text { on science) } \\
\text { (6) OWN_edu (use of ICTs by the teacher for his } \\
\text { information on school subjects) }\end{array}$ \\
\hline$\eta_{2}$ & SUCC_S & $\begin{array}{l}\text { Success in the use of ICTs by the } \\
\text { teacher for the benefit of the student. }\end{array}$ & $\begin{array}{l}\text { (1) TEACH (use of ICTs by the teacher for teaching) } \\
\text { (2) TEACH2 } \\
\text { (3) TYPE (use and management of software and hardware } \\
\text { in teaching) } \\
\text { (4) TYPE1 (using word processing software and } \\
\text { spreadsheets in teaching) } \\
\text { (5) TYPE2 (software and hardware management in } \\
\text { teaching) }\end{array}$ \\
\hline$\xi_{1}$ & PRECONC* & Disposition of teachers in ICTs. & (1) PRECONC (self-assessment) \\
\hline$\xi_{2}$ & $\mathrm{SCHOOL}^{*}$ & $\begin{array}{l}\text { Influence of school environment in } \\
\text { the use of ICTs. }\end{array}$ & (1) SCHOOL (environment of creative challenges) \\
\hline$\xi_{3}$ & FEAR* & Phobia of teachers for ICTs. & (1) FEAR (feelings of fear) \\
\hline
\end{tabular}

Source: Keramida, 2010.

Depending on the version of model that was investigated, similar parameters are used. The paper investigates the seven instances of the model with path diagrams, tables, and equations. Also, presented in a concise manner, the maximum likelihood estimates for all models and finally becomes a commentary on the seven cases of the model. In the paper we focused on the models M2 which is the more important than the others.

\section{The Empirical Application of Model $\mathbf{M}_{2}$}

The model M2 exams if the success in the use of ICTs by the teacher for the benefit of his students affects the way he uses ICTs for their own benefit. This relationship considers that the phobia and the predisposition of the ICTs influence the teacher's behaviour. The variables of the model M2 are the following: 
Table 2. Endogenous Latent Variables

Source: Keramida, 2010.

\begin{tabular}{|c|c|}
\hline VARIABLE OF LVM & VARIABLE OF EMPIRICAL MODEL M \\
\hline$n_{1}$ & SUCC_T ${ }^{*}$ \\
\hline$n_{2}$ & SUCC_S* \\
\hline
\end{tabular}

Table 3. Exogenous Latent Variables

Source: Keramida, 2010.

\begin{tabular}{|c|c|}
\hline VARIABLE OF LVM & VARIABLE OF EMPIRICAL MODEL M \\
\hline$\xi_{1}$ & PRECONC* $^{*}$ \\
\hline$\xi_{2}$ & FEAR* $^{*}$ \\
\hline
\end{tabular}

Table 4. Indicators of Endogenous Latent Variables

\begin{tabular}{|c|c|}
\hline VARIABLE OF LVM & VARIABLE OF EMPIRICAL MODEL M \\
\hline $\mathrm{y}_{1}$ & ADM \\
\hline $\mathrm{y}_{2}$ & PREP \\
\hline $\mathrm{y}_{3}$ & OWN_ed \\
\hline $\mathrm{y}_{4}$ & TEACH2 \\
\hline $\mathrm{y}_{5}$ & TYPE1 \\
\hline $\mathrm{y}_{6}$ & TYPE2 \\
\hline
\end{tabular}

Source: Keramida, 2010.

Table 5. Indicators of Exogenous Latent Variables

\begin{tabular}{|c|c|}
\hline VARIABLE OF LVM & VARIABLE OF EMPIRICAL MODEL M \\
\hline $\mathrm{x}_{1}$ & PRECONC \\
\hline $\mathrm{x}_{2}$ & FEAR \\
\hline
\end{tabular}

Source: Keramida, 2010.

The path diagram of the model is the following:

Figure 2. Path Diagram of Model $\mathrm{M}_{2}$

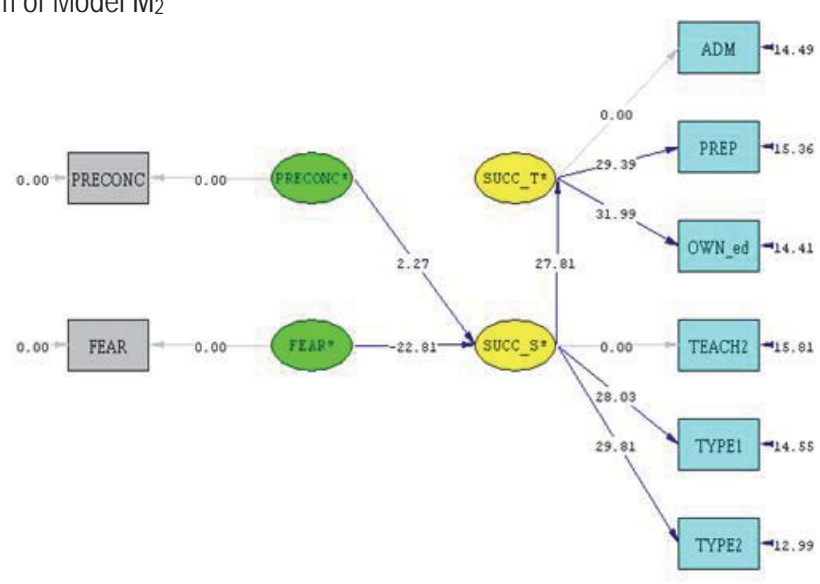

Chi-squar $e^{2}=282.23, d f=18, p-v a l u e=0.00000, \quad R M S E A=0.156$

Source: Keramida, 2010. 
The path diagram of the model $\mathrm{M} 2$ is an alternative presentation of general model and describes the relationships of the variables that are valued in a structural part of the model M2, with yellow and green circles, as well as the measurement models, with grey and blue squares. The arrows show the relationships of cause among variables. All relationships are one-sided. The values next to each arrow are the statistic $t$ values for each factor, and the interpretation is the same as below.

The estimation of the model M2 and the path diagram show the following:

1. there is an one-sided positive and statistically significant effect of the variable SUCC_S * in the variable SUCC_ $T^{*}$. This means that the success in the use of ICTs by the teacher to the student, affects positively on rate $\beta_{12}=1.0073$ success in the use of ICTs by the teacher for his own benefit. if successful use of ICTs by the teacher to the students increased by one unit, then the success in the use of ICTs by the professor for his own interest will grow at 1.0073 .

2. the variable PRECONC *, as the tendency of teachers in ICTs, affect only the variable SUCC_S * with positive correlation with rate $\gamma_{21}=0.0906$ and is statistically significant.

3. in addition, the variable FEAR *, the phobia for ICTs has a small but negative and statistically significant effect on variable SUCC_S * with a coefficient of $\gamma_{22}=-0.4520$.

The model $\mathrm{M}_{2}$ has the following format:

$$
\begin{gathered}
\eta=\mathrm{B} \eta+\Gamma \xi+\zeta \\
\chi=\Lambda_{x} \xi+\delta \\
y=\Lambda_{y} \eta+\varepsilon
\end{gathered}
$$

Structure Model

$\left[\begin{array}{l}\eta_{1} \\ \eta_{2}\end{array}\right]=\left[\begin{array}{cc}0 & \beta_{12} \\ 0 & 0\end{array}\right]\left[\begin{array}{l}\eta_{1} \\ \eta_{2}\end{array}\right]+\left[\begin{array}{cc}0 & 0 \\ \gamma_{21} & \gamma_{22}\end{array}\right]\left[\begin{array}{l}\xi_{1} \\ \xi_{2}\end{array}\right]+\left[\begin{array}{l}\zeta_{1} \\ \zeta_{2}\end{array}\right]$

Measurments Models

$\left[\begin{array}{l}x_{1} \\ x_{2}\end{array}\right]=\left[\begin{array}{ll}1 & 0 \\ 0 & 1\end{array}\right]\left[\begin{array}{l}\xi_{1} \\ \xi_{2}\end{array}\right]+\left[\begin{array}{l}\delta_{1} \\ \delta_{2}\end{array}\right]$

$\left[\begin{array}{l}y_{1} \\ y_{2} \\ y_{3} \\ y_{4} \\ y_{5} \\ y_{6}\end{array}\right]=\left[\begin{array}{cc}\lambda_{1} & 0 \\ \lambda_{2} & 0 \\ 0 & \lambda_{3} \\ 0 & \lambda_{4} \\ 0 & \lambda_{5} \\ 0 & \lambda_{6}\end{array}\right]\left[\begin{array}{l}\eta_{1} \\ \eta_{2}\end{array}\right]+\left[\begin{array}{l}\varepsilon_{1} \\ \varepsilon_{2} \\ \varepsilon_{3} \\ \varepsilon_{4} \\ \varepsilon_{5} \\ \varepsilon_{6}\end{array}\right]$

The equations of model $\mathrm{M} 2$ are the following:

$$
\begin{aligned}
& \eta_{1}=\beta_{12} \eta_{2}+\zeta_{1} \\
& \eta_{2}=\gamma_{21} \xi_{1}+\gamma_{22} \xi_{2}+\zeta_{2} \\
& \chi_{1}=1 \xi_{1}+\delta_{1} \\
& \chi_{2}=1 \xi_{1}+\delta_{2} \\
& y_{1}=\lambda_{1} \eta_{1}+\varepsilon_{1} \\
& y_{2}=\lambda_{2} \eta_{1}+\varepsilon_{2} \\
& y_{3}=\lambda_{3} \eta_{1}+\varepsilon_{3} \\
& y_{4}=\lambda_{4} \eta_{2}+\varepsilon_{4} \\
& y_{5}=\lambda_{5} \eta_{2}+\varepsilon_{5} \\
& y_{6}=\lambda_{6} \eta_{2}+\varepsilon_{6}
\end{aligned}
$$

The first 2 equations is the structural part of our model, equations 3 and 4 give us the measurement models for exogenous latent variables and finally the equations 5 to 10 give us the measurement models for endogenous latent 
variables. There is one-sided relationship between endogenous latent variable, equation 1 , whereas in equation 2 there is the relationship for variable $\eta_{2}$ which is only affected by exogenous latent variables. In addition we give unit fixed price $(\lambda=1)$ on the coefficients of the exogenous latent variables.

The econometric estimation of the model $\mathrm{M}_{2}$ using LISREL program creates the following equations:

$$
\begin{array}{rl}
\eta_{1}=1 & .0073 \eta_{2} \\
& (27.81) \\
\eta_{2}= & 0.0906 \xi_{1}-0.4520 \xi_{2} \\
\chi_{1}=1 \xi_{1} & (2.27) \quad(-22.81) \\
\chi_{2}=1 \xi_{1} & \\
y_{1}=0 & 0.7650 \eta_{1}+14.49 \\
y_{2}= & 0.7577 \eta_{1}+15.36 \\
& (29.39) \\
y_{3}= & 0.7264 \eta_{1}+14.41 \\
& (31.99) \\
y_{4}= & 0.9423 \eta_{2} \\
y_{5}=0 & 0.8622 \eta_{2}+14.55 \\
& (28.03) \\
y_{6}= & 0.8757 \eta_{2}+12.99 \\
& (29.81)
\end{array}
$$

\section{GFI= 0.8956}

The following co-variance matrix is based on 606 observed variables

Table 6. Covariance Matrix of model $\mathrm{M}_{2}$

\begin{tabular}{|c|c|c|c|c|c|c|c|c|}
\hline & $y_{1}$ & $y_{2}$ & $y_{3}$ & $y_{4}$ & $y_{5}$ & $y_{6}$ & $x_{1}$ & $x_{2}$ \\
\hline$y_{1}$ & 0.7514 & & & & & & & \\
\hline$y_{2}$ & 0.5580 & 0.7943 & & & & & & \\
\hline$y_{3}$ & 0.5530 & 0.5743 & 0.6743 & & & & & \\
\hline$y_{4}$ & 0.7286 & 0.7663 & 0.6663 & 1.3006 & & & & \\
\hline$y_{5}$ & 0.6342 & 0.7147 & 0.6247 & 0.7765 & 0.9419 & & & \\
\hline$y_{6}$ & 0.6990 & 0.6171 & 0.6421 & 0.8332 & 0.7774 & 0.9086 & & \\
\hline$x_{1}$ & -0.001 & 0.1097 & 0.0497 & 0.0365 & 0.0869 & 0.0199 & 0.4519 & \\
\hline$x_{2}$ & -1.0869 & -0.9801 & -1.0001 & -1.3078 & -0.0810 & -1.1701 & -0.0360 & 2.9547 \\
\hline
\end{tabular}

Source: Keramida, 2010

The results of the estimation of the model M2 show that:

\subsection{A Structural part of the Model}

The variable $\eta_{2}$ affects positively the variable $\eta_{1}$ with rate $\beta_{12}=1.0073$ and is statistically significant $(t-$ stat $=27.81)$.

Respectively note that variable $\eta_{2}$ is affected by the exogenous latent variables $\xi_{1}$ and $\xi_{2}$. Specifically we show that the variable $\xi_{1}$ act positively in the variable $\eta_{2}$, with rate $\gamma_{21}=0.0906$ and is statistically significant $(t-$ stat $=2.27)$, while the variable $^{\xi_{2}}$ affects negatively the variable $\eta_{2}$, with rate $\gamma_{22}=-0.4520$ and is statistically significant $(t-$ stat $=-22.81)$.

\subsection{The Measuring Model of Exogenous Latent Variables}

The coefficients of the exogenous variables that have unit fixed price $(\lambda=1)$. We observe that the $\xi_{1}$ was measured by indicators $\chi_{1}$ and $\chi_{2}$ respectively. 


\subsection{The Measuring Model of Endogenous Latent Variables}

We note that the variable $\eta_{1}$ was measured by indicators $y_{1}, y_{2}$ and $y_{3}$. The variable $\eta_{2}$ was measured by indicators $y_{4}$, $y_{5}$ and $y_{6}$. And here we have positive signs on the coefficients and is also statistically significant at the $1 \%$ significance level. We note that in equations 5 and 8 are not given by the LISREL software the ${ }^{t-\text { stat }}$ of rates because the endogenous indicators $y_{1}$ and $y_{4}$ are considered as reference indicators. Below are summarised for all models (M1M7) the maximum likelihood estimates.

Table 7. Maximum Likelihood Estimates of Models M1-M7(T-values)

\begin{tabular}{|c|c|c|c|c|c|c|c|}
\hline Parameter & & & & & & & \\
\hline & $M_{1}$ & $M_{2}$ & $M_{3}$ & $M_{4}$ & $M_{5}$ & $M_{6}$ & $M_{7}$ \\
\hline$\beta_{12}$ & $\begin{array}{l}1.0635 \\
(26.23)\end{array}$ & $\begin{array}{l}1.0073 \\
(27.81)\end{array}$ & & & & & $\begin{array}{l}0.4826 \\
(18.68)\end{array}$ \\
\hline$\beta_{21}$ & $\begin{array}{c}0.4962 \\
(3.18)\end{array}$ & & $\begin{array}{l}0.9931 \\
(27.15)\end{array}$ & $\begin{array}{l}1.0410 \\
(26.35)\end{array}$ & $\begin{array}{l}0.2179 \\
(6.67)\end{array}$ & $\begin{array}{l}0.2617 \\
(13.09)\end{array}$ & $\begin{array}{l}0.1215 \\
(7.59) \\
\end{array}$ \\
\hline$y_{11}$ & $\begin{array}{l}0.0255 \\
(1.76)\end{array}$ & & $\begin{array}{l}0.898 \\
(2.25)\end{array}$ & $\begin{array}{l}0.7642 \\
(17.60)\end{array}$ & $\begin{array}{l}0.4971 \\
(15.41)\end{array}$ & $\begin{array}{l}0.5765 \\
(17.18)\end{array}$ & $\begin{array}{l}0.5569 \\
(18.14)\end{array}$ \\
\hline$y_{12}$ & & & $\begin{array}{l}-0.4532 \\
(-25.04)\end{array}$ & $\begin{array}{c}-0.1463 \\
(-6.84)\end{array}$ & $\begin{array}{l}0.012 \\
(0.40)\end{array}$ & $\begin{array}{c}-0.0005 \\
(-0.03)\end{array}$ & \\
\hline$y_{13}$ & & & & & $\begin{array}{l}0.5569 \\
(18.34)\end{array}$ & $\begin{array}{l}0.5270 \\
(21.70)\end{array}$ & \\
\hline$y_{21}$ & & $\begin{array}{c}0.0906 \\
(2.27)\end{array}$ & & & & & \\
\hline$y_{22}$ & $\begin{array}{c}-0.3594 \\
(-2.69)\end{array}$ & $\begin{array}{l}-0.4520 \\
(-22.81)\end{array}$ & & $\begin{array}{c}0.0223 \\
(1.45)\end{array}$ & $\begin{array}{l}0.044 \\
(3.73)\end{array}$ & $\begin{array}{c}0.0223 \\
(3.33)\end{array}$ & $\begin{array}{l}0.8949 \\
(29.78)\end{array}$ \\
\hline$y_{23}$ & & & & & $\begin{array}{l}0.8493 \\
(20.51)\end{array}$ & $\begin{array}{l}0.7760 \\
(48.48)\end{array}$ & \\
\hline$\lambda y_{1}$ & 0.7541 & 0.7650 & 0.7674 & 1.2623 & 1.2577 & 1.2583 & 0.7673 \\
\hline$\lambda y_{2}$ & $\begin{array}{l}0.7410 \\
(27.90)\end{array}$ & $\begin{array}{l}0.7577 \\
(29.39)\end{array}$ & $\begin{array}{l}0.7597 \\
(29.54)\end{array}$ & $\begin{array}{l}1.1062 \\
(37.78)\end{array}$ & $\begin{array}{l}1.1238 \\
(38.95)\end{array}$ & $\begin{array}{l}1.1259 \\
(39.12)\end{array}$ & $\begin{array}{l}0.7793 \\
(31.20)\end{array}$ \\
\hline$\lambda y_{3}$ & 0.9486 & $\begin{array}{l}0.7264 \\
(31.99)\end{array}$ & $\begin{array}{l}0.7315 \\
(32.49)\end{array}$ & $\begin{array}{l}0.9726 \\
(36.63)\end{array}$ & $\begin{array}{l}0.9522 \\
(34.09)\end{array}$ & $\begin{array}{l}0.9542 \\
(34.24)\end{array}$ & $\begin{array}{l}0.6979 \\
(29.38)\end{array}$ \\
\hline$\lambda y_{4}$ & $\begin{array}{l}0.8652 \\
(28.38)\end{array}$ & 0.9423 & 0.9425 & 0.9629 & 1.1115 & 1.1118 & 1.1209 \\
\hline$\lambda y_{5}$ & $\begin{array}{l}0.8795 \\
(30.13)\end{array}$ & $\begin{array}{l}0.8622 \\
(28.03)\end{array}$ & $\begin{array}{l}0.8653 \\
(28.10)\end{array}$ & $\begin{array}{l}0.8675 \\
(29.94)\end{array}$ & $\begin{array}{l}0.7244 \\
(27.01)\end{array}$ & $\begin{array}{l}0.7238 \\
(26.97)\end{array}$ & $\begin{array}{l}0.7068 \\
(25.66)\end{array}$ \\
\hline$\lambda^{y_{6}}$ & & $\begin{array}{l}0.8757 \\
(29.81)\end{array}$ & $\begin{array}{l}0.8837 \\
(30.05)\end{array}$ & $\begin{array}{l}0.8640 \\
(30.75)\end{array}$ & $\begin{array}{l}0.7504 \\
(30.45)\end{array}$ & $\begin{array}{l}0.7502 \\
(30.44)\end{array}$ & $\begin{array}{l}0.7471 \\
(30.23)\end{array}$ \\
\hline$\lambda^{x_{1}}$ & $\begin{array}{l}0.6722 \\
(34.79)\end{array}$ & 1.0000 & 1.0000 & 1.0000 & $\begin{array}{l}0.8605 \\
(34.79)\end{array}$ & 1.0000 & $\begin{array}{l}0.8605 \\
(34.79)\end{array}$ \\
\hline$\lambda x_{2}$ & $\begin{array}{l}1.7189 \\
(34.79)\end{array}$ & 1.0000 & 1.0000 & 1.0000 & $\begin{array}{l}1.7189 \\
(34.79)\end{array}$ & 1.0000 & $\begin{array}{l}1.0305 \\
(34.79)\end{array}$ \\
\hline$\lambda x_{3}$ & & & & & $\begin{array}{l}1.0214 \\
(33.74)\end{array}$ & 1.0000 & \\
\hline $\mathbf{R}^{2} \times 1$ & 1.0000 & 1.0000 & 1.0000 & & 1.0000 & & 1.0000 \\
\hline$R^{2} \times 2$ & 1.0000 & 1.0000 & 1.0000 & & 1.0000 & & 1.0000 \\
\hline $\mathbf{R}^{2} \times 3$ & & & & & 0.9825 & & \\
\hline$R^{2}{ }^{Y} 1$ & 0.7581 & 0.7789 & 0.7837 & 0.8439 & 0.8378 & 0.8386 & 0.7836 \\
\hline $\mathbf{R}^{2}{ }^{2}$ & 0.6924 & 0.7229 & 0.7267 & 0.8186 & 0.8449 & 0.8482 & 0.7646 \\
\hline $\mathrm{R}^{2} \mathrm{Y} 3$ & 0.6925 & 0.7827 & 0.7935 & 0.8014 & 0.7681 & 0.7714 & 0.7225 \\
\hline$R^{2} Y_{4}$ & 0.7950 & 0.6827 & 0.6830 & 0.7129 & 0.9499 & 0.9505 & 0.9661 \\
\hline $\mathbf{R}^{2}{ }{ }^{2}$ & 0.8522 & 0.7894 & 0.7949 & 0.7990 & 0.5571 & 0.5563 & 0.5304 \\
\hline $\mathbf{R}^{2}{ }{ }_{6}$ & & 0.8476 & 0.8594 & 0.8217 & 0.6197 & 0.6195 & 0.6143 \\
\hline$\delta_{3}$ & & & & & 1.87 & & \\
\hline
\end{tabular}




\begin{tabular}{|c|c|c|c|c|c|c|c|}
\hline Parameter & & & & & & & \\
\hline & $M_{1}$ & $M_{2}$ & $M_{3}$ & $M_{4}$ & $M_{5}$ & $M_{6}$ & $M_{7}$ \\
\hline$\varepsilon_{1}$ & 13.21 & 14.49 & 14.30 & 14.20 & 13.81 & 13.76 & 14.12 \\
\hline$\varepsilon_{2}$ & 14.81 & 15.36 & 15.18 & 14.79 & 13.59 & 13.47 & 14.51 \\
\hline$\varepsilon_{3}$ & 15.36 & 14.41 & 14.10 & 15.09 & 15.20 & 15.09 & 15.15 \\
\hline$\varepsilon_{4}$ & 13.80 & 15.81 & 15.63 & 15.97 & 10.35 & 10.25 & 8.25 \\
\hline$\varepsilon_{5}$ & 11.91 & 14.55 & 14.11 & 14.84 & 17.63 & 17.62 & 17.37 \\
\hline$\varepsilon_{6}$ & & 12.99 & 11.94 & 14.30 & 17.58 & 17.57 & 17.32 \\
\hline$\sigma^{2} \bar{\gamma}$ & & & & & $\begin{array}{l}0.0186 \\
(0.01)\end{array}$ & & \\
\hline$\sigma_{\varepsilon 1}^{2}$ & $\begin{array}{l}0.1814 \\
(0.01)\end{array}$ & $\begin{array}{l}0.1661 \\
(0.01)\end{array}$ & $0.1625(0.01)$ & $\begin{array}{l}0.2948 \\
(0.02)\end{array}$ & $\begin{array}{c}0.3063 \\
(0.02)\end{array}$ & $\begin{array}{l}0.3048 \\
(0.02)\end{array}$ & $\begin{array}{c}0.1626 \\
(0.01)\end{array}$ \\
\hline$\sigma^{2} \varepsilon 2$ & $0.2439(0.02)$ & $\begin{array}{l}0.2200 \\
(0.01)\end{array}$ & $\begin{array}{l}0.2171 \\
(0.01)\end{array}$ & $\begin{array}{l}0.271 \\
(0.02)\end{array}$ & $\begin{array}{c}0.2317 \\
(0.02)\end{array}$ & $\begin{array}{l}0.2270 \\
(0.02)\end{array}$ & $\begin{array}{c}0.1870 \\
(0.02)\end{array}$ \\
\hline$\sigma_{\varepsilon 3}^{2}$ & $\begin{array}{l}0.3997 \\
(0.03)\end{array}$ & $\begin{array}{l}0.1465 \\
(0.01)\end{array}$ & $\begin{array}{l}0.1392 \\
(0.01)\end{array}$ & $\begin{array}{l}0.2344 \\
(0.02)\end{array}$ & $\begin{array}{c}0.2737 \\
(0.02)\end{array}$ & $\begin{array}{l}0.2699 \\
(0.02)\end{array}$ & $\begin{array}{c}0.1871 \\
(0.01)\end{array}$ \\
\hline$\sigma_{\varepsilon 4}^{2}$ & $0.1925(0.01)$ & $\begin{array}{l}0.4126 \\
(0.03)\end{array}$ & $\begin{array}{c}0.4122 \\
(0.03)\end{array}$ & $\begin{array}{l}0.3733 \\
(0.02)\end{array}$ & $\begin{array}{c}0.0651 \\
(0.01)\end{array}$ & $\begin{array}{c}0.0644 \\
(0.01)\end{array}$ & $\begin{array}{l}0.0441 \\
(0.01)\end{array}$ \\
\hline$\sigma_{\varepsilon 5}^{2}$ & $\begin{array}{l}0.1342 \\
(0.01)\end{array}$ & $0.1984(0.01)$ & $\begin{array}{l}0.1932 \\
(0.01)\end{array}$ & $\begin{array}{l}0.1893 \\
(0.01)\end{array}$ & $\begin{array}{c}0.4172 \\
(0.02)\end{array}$ & $\begin{array}{l}0.4179 \\
(0.02)\end{array}$ & $\begin{array}{c}0.4424 \\
(0.03)\end{array}$ \\
\hline$\sigma_{\varepsilon 6}^{2}$ & & $\begin{array}{l}0.1384 \\
(0.01)\end{array}$ & $\begin{array}{l}0.1277 \\
(0.01)\end{array}$ & $\begin{array}{l}0.1620 \\
(0.01)\end{array}$ & $\begin{array}{l}0.3455 \\
(0.02)\end{array}$ & $\begin{array}{l}0.3457 \\
(0.02)\end{array}$ & $\begin{array}{c}0.3504 \\
(0.02)\end{array}$ \\
\hline Degrees of Freedom & 11 & 18 & 18 & 17 & 20 & 21 & 17 \\
\hline $\begin{array}{c}X^{2} \\
\text { (Prob.) }\end{array}$ & $\begin{array}{c}238.34 \\
(0.00)\end{array}$ & $\begin{array}{c}282.23 \\
(0.00)\end{array}$ & $\begin{array}{l}293.27 \\
(0.00)\end{array}$ & $\begin{array}{c}370.08 \\
(0.00)\end{array}$ & $\begin{array}{c}1070.36 \\
(0.00)\end{array}$ & $\begin{array}{c}1079.74 \\
(0.00)\end{array}$ & $\begin{array}{c}1001.71 \\
(0.00)\end{array}$ \\
\hline GFI & 0.8988 & 0.8956 & 0.8919 & 0.8674 & 0.7178 & 0.7160 & 0.7073 \\
\hline AGFI & 0.74248 & 0.7911 & 0.7838 & 0.7191 & 0.3650 & 0.3915 & 0.3801 \\
\hline RMSR & 0.0346 & 0.0311 & 0.0316 & 0.0362 & 0.1083 & 0.1087 & 0.0975 \\
\hline
\end{tabular}

Source: Keramida, 2010.

The model M2 investigates the relationship that develops between the use of ICTs by the teacher for the benefit of the student (SUCC_S *) and the use of ICTs by the teacher for his own benefit (SUCC_T *). For this purpose are taken into account the predisposition of teachers impact on the transmission of knowledge of teachers through ICTs (PRECONC *) and their phobia (FEAR*). The variables SUCC_T * and SUCC_S * are endogenous latent variables and PRECONC * and FEAR * are the exogenous latent variables.

This model represents a complete model LISREL. The first equation is the structural model, and the next two equations represent the measurement models. From the tables LAMBDA- Y, LAMBDA-X, BETA, GAMMA, PSI, THETADELTA, THETA- EPS and 18 free parameters are derived to estimate. According to the identification of model we have: $\mathrm{t} \leq \frac{(\mathrm{p}+\mathrm{q})(\mathrm{p}+\mathrm{q}+1)}{2} \Rightarrow 18 \leq \frac{8 \times 9}{2} \Rightarrow 18 \leq 36$ so our model is perfectly identified while the degrees of freedom is $36-18=18$.

The maximum likelihood estimates for matrixs LAMBDA-Y, LAMBDA-X, BETA, GAMMA, PSI, THETA-DELTA, THETA-EPS and the correlation coefficients, $R^{2}$, for the rates $Y$ and $X$ are:
$\mathrm{R}^{2}{ }^{2} 1=0.7789$
$\mathrm{R}^{2} \mathrm{y}_{2}=0.7229$
$\mathrm{R}^{2} \mathrm{y}_{3}=0.7827$
$R^{2}{ }^{y} 4=0.6827$
$\mathrm{R}^{2} \mathrm{y}_{5}=0.7894$
$R^{2}{ }^{y 6}=0.8476$
$R^{2} \times 1=1.00000$
$R^{2} \times 2=1.00000$ 
All the above rates are satisfying. Adaptation measures GFI, AGFI is almost perfect. The GFI equals 0.8956 and AGFI is too high, 0.7911 . In addition, the value of RMR is satisfying and is equal to 0.0311 .

Of the most important pieces in each program LISREL is the t-values obtained with the use of standard errors. We have the standard errors and the t-values for matrixs LAMBDA-Y, LAMBDA-X, BETA, GAMMA, PSI, THETA-DELTA, THETA-EPS. All t-values are satisfactory $(>2)$ except of the matrix GAMMA which has a negative t-value $(-22.81)$ that is far less than 2.

In conclusion, the use of ICTs by the teacher for the transmission of knowledge affects positively the use of ICTs for his personal benefit, helping in his professional development. Of course, important role in the use of ICTs by the teacher for the benefit of pupils have prejudices and phobias of teachers for ICTs, which have a negative effect.

In addition, the use of ICTs by the teacher for the course preparation (PREP) and the use of ICTs by the teacher for being informed on his science (OWN_ed) are considered as a success in the use of ICTs by the teacher for his own benefit and personal needs. The use of word-processing software, spreadsheets (TYPE1) and software and hardware management in teaching are types of successful use of ICTs by the teacher for the benefit of the students (TYPE2). Based on the above, we concluded that the use of ICTs by the teacher for the transmission of knowledge contribute positively to enhancing the use of ICTs for their own benefit.

\section{Conclusions}

Useful conclusions are based on the results of the survey. The findings will help the institutions of education and the teachers to contribute to efficient and comprehensive integration of ICTs in the educational process. According to the theoretical framework that was applied on the basis of estimations of seven models, shows that ICTs are considered invaders that disrupt the already existing school environment both from teachers, who are the key elements of the school, and from students.

Specifically, the research results concluded that the fears and prejudices of the ICTs teachers are responsible for their negative attitude to them and affect inhibitory the integration into the educational process. Teachers perceive ICTs as intruders threatening the balance of their environment and for this reason reject the ICTs. Therefore, the effective solution to counter this negative situation is the provision of appropriate incentives from the school environment to the teachers. So, teachers will be able to overcome negative emotions and use of ICTs in teaching. Moreover, the successful integration of computers into the educational process in the context of the ecosystem of the school, depends on their compatibility with the teaching environment.

In addition, the paper shows how the use of ICTs by the teacher for personal benefit, affects the transmission of knowledge positively. Therefore, we should find ways to strengthen teacher training in the use of ICTs, which will contribute to their integration in the educational practice. In addition, the use of ICTs by the teacher during the teaching process contributes positively to ICTs application for personal development and facilitates students in understanding the lesson.

The integration of ICTs in the educational process is greatly influenced by the school environment. In a favorableto-ICTs school environment with creative challenges, the teacher who is trained in ICTs manages to successfully introduce them into the educational process. An adequate logistical equipment and harmonious collaboration with colleagues working in the same business premises create a favorable environment for the introduction of ICTs in teaching. In contrast, in the case that the school environment does not provide incentives to learning, ICTs are not embedded in the educational practice.

Summarizing the results of the thesis we concluded that the integration of ICTs in the educational process requires teachers who do not have phobias and prejudices about ICTs and operate in favorable school environment. With the term "favorable-to-ICTs school environment" is described a school that constantly strengthens teachers in ICTs use and gives them incentives and motives for continuous updating and development. The teachers and the school environment should stop to consider ICTs as invaders, aimed at disruption of the school, acting menacingly and parasitically. In contrast, ICTs should be examined as elements of improvement and evolution of both teachers and the school environment.

\section{Discussion}

With regard to the prospects for further investigation, it is proposed to be a research that would cover also other prefectures of Greece. It would be interesting to investigate, in a first phase the degree in which the ecosystemic 
theoretical frame constitutes a powerful tool for the interpretation of the use of ICTs in schools that belong in other prefectures of Greece and in second phase the degree in which the results of this research are common with the results of the researches that will be realized in the other prefectures.

Also, it would be important a future research to concern other specialities of teachers and other educational levels, so that there would be a comparison of the results in order to have useful conclusions. Besides, it would be interesting to conduct a research in the school population that studies in the educational institutions of secondary education in the prefecture of Thessaloniki. For this purpose we would use the tools and theoretical ecosystemic frame, so that a convergence or divergence between the results of the two researches is realized. Finally, we should expand the research in the school populations to generalize itself on one side also in other prefectures of Greece and on the other side in other educational levels so as we reach useful conclusions.

\section{References}

Amartya, S. (1999). Development as Freedom, Anchor Books: New York.

Ana, M. \& Veiga, S. (2002). Teaching, training and learning strategies in today's school. Developing reflective practices. European Conference on Educational Research - School of Phsychology and Educational Sciences University of Lisbon, 1-16.

Becker, H. J.. (2000a). Findings from the teaching, learning, and computing survey: is Larry Cuban right?. Education Policy Analysis Archives, 8 (51), 2-32.

Cattagni, A. \& Farris, E. ( 2001). Internet Access in U.S. Public Schools and Classrooms: 1994 - 2000. Washington DC: National Center for Educational Statistics.

Cuban, L. (1999). The technology puzzle: why is greater access not translating into better classroom use?. Education Week, 47-68.

Gujarati N. D. (1988). Basic Econometrics. McGraw-Hill Book Company.

Gunilla, J. \& Jorden, N. (2004). ICT in the classroom: is doing more important than knowing?. Education and Information Technologies, $9(1), 37-45$.

Kasimati, K. \& Gialamas, B. (2001). Teachers ' opinions about the contributions of new technologies in educational process. Survey Of Educational Affairs, 114-125.

Keramida, K. (2010). The adoption of Information and Communication Technologies (ICTs) in the teaching of mathematics in secondary schools: an ecosystemic approach (Doctoral dissertation, University of Macedonia). Available from National Archive of PhdTheses (http://www.didaktorika.gr//eadd/handle/10442/18940).

Kynigos C. (2001). New practices with new tools in the classroom: educating teacher trainers in Greece to generate a "school community use of new technologies, Themes in Education, 2 (4), 381-399.

$\mathrm{Li}, \mathrm{Q}$.(2003). Would we teach without technology? A professor's experience of teaching mathematics education incorporating the internet. Educational Research, 45 (1), 61-77.

Loveless, T. (1996). Why aren't computers used more in schools?. Educational Policy, 10(4), 448-467.

Triantafyllou, S. (2002). The application of new technologies in educational process in European countries. Thesis prepared at the Department in Information Systems, MIS/25

Wendy, M. (2001). Not just tools: the role of E-technologies in culture of learning. Education, Communication \& Information, 1 (2), 229235.

Zhao, Y. \& Frank, K. (2003). Factors affecting technology uses in schools: an ecological perspective. American Educational Research Journal, 40(4), 807-840. 